\title{
Mitral Valve Surgery via Upper Ministernotomy: Single-Centre Experience in More than 400 Patients
}

\author{
Medhat Radwan ${ }^{1}{ }^{\circledR}$, Christoph Salewski $^{1}{ }^{1}$, Florian Hecker ${ }^{2}$, Aleksandra Miskovic ${ }^{2}$, Petar Risteski ${ }^{1}$, \\ Jan Hlavicka $\left.{ }^{2}{ }^{(}\right)$, Anton Moritz ${ }^{2}$, Thomas Walther ${ }^{2}$ and Tomas Holubec ${ }^{2, *}(\mathbb{D}$ \\ 1 Division of Thoracic and Cardiovascular Surgery, University of Tübingen, 72076 Tübingen, Germany; \\ medhat.radwan@med.uni-tuebingen.de (M.R.); christoph.salewski@uni-tuebingen.de (C.S.); \\ Petar.Risteski@med.uni-tuebingen.de (P.R.) \\ 2 Department of Cardiovascular Surgery, University Hospital Frankfurt, Johann Wolfgang Goethe University \\ Frankfurt, 60590 Frankfurt am Main, Germany; florian.hecker@kgu.de (F.H.); \\ Aleksandra.Miskovic@kgu.de (A.M.); Jan.Hlavicka@kgu.de (J.H.); moritzanton@web.de (A.M.); \\ Thomas.Walther@kgu.de (T.W.) \\ * Correspondence: tomasholubec@email.cz; Tel.: +49-69630180094
}

check for updates

Citation: Radwan, M.; Salewski, C.; Hecker, F.; Miskovic, A.; Risteski, P.; Hlavicka, J.; Moritz, A.; Walther, T.; Holubec, T. Mitral Valve Surgery via Upper Ministernotomy: Single-Centre Experience in More than 400 Patients. Medicina 2021, 57, 1179. https://doi.org/10.3390/ medicina57111179

Academic Editor: Andrea Mingoli

Received: 29 September 2021

Accepted: 27 October 2021

Published: 30 October 2021

Publisher's Note: MDPI stays neutral with regard to jurisdictional claims in published maps and institutional affiliations.

Copyright: (C) 2021 by the authors. Licensee MDPI, Basel, Switzerland. This article is an open access article distributed under the terms and conditions of the Creative Commons Attribution (CC BY) license (https:/ / creativecommons.org/licenses/by/ $4.0 /)$.

\begin{abstract}
Background: Minimally invasive mitral valve (MV) surgery has emerged as an alternative to conventional sternotomy aiming to decrease surgical trauma. The aim of the study was to describe our experience with minimally invasive MV surgery through partial upper sternotomy (PUS) regarding short- and long-term outcomes. Methods: From January 2004 through March 2014, 419 patients with a median age of 58.9 years (interquartile range 18.7; 31.7\% females) underwent isolated primary MV surgery using PUS. Myxomatous degenerative MV disease was the predominant pathology (77\%). The patients' mean EuroSCORE II risk profile was $3.9 \pm 3.6 \%$. Results: Mitral valve repair was performed in 384 patients $(91.6 \%)$ and replacement in 35 patients $(8.4 \%)$. Thirty-day mortality was $3.1 \%$. In total, $29(6.9 \%)$ deaths occurred during the follow-up. The overall estimated survival at 1,5 , and 10 years was $93.1 \pm 1.3 \%, 87.1 \pm 1.9 \%$, and $81.1 \pm 3.4 \%$. Reoperation was necessary in $14(3.3 \%)$ patients. The overall freedom from MV reoperation at 1, 5, and 10 years was $98.2 \pm 0.7 \%$, $96.1 \pm 1.2 \%$, and $86.7 \pm 6.7 \%$ and the overall freedom from recurrent MV regurgitation $>$ grade 2 in repaired valves at 1,5 , and 10 years was $98.8 \pm 0.6 \%, 98.8 \pm 0.6 \%$, and $94.6 \pm 3.3 \%$. Conclusions: Minimally invasive MV surgery via PUS can be performed with particularly good early and late results. Thus, the PUS approach with the use of standard surgical instruments and cannulation techniques can be a valuable option for the MV surgery either in patients contraindicated or not suitable to minithoracotomy.
\end{abstract}

Keywords: minimally invasive surgery; mitral valve surgery; partial upper sternotomy

\section{Introduction}

Minimally invasive cardiac surgery continues to grow in popularity owing to improvements in surgical technique and technology, together with the acceptance of minimally invasive approaches for operations previously performed through a conventional median sternotomy [1-4]. A variety of minimally invasive approaches to the mitral valve (MV) have been developed in the early 1990s aiming to decrease the surgical trauma by minimizing the size of incisions and modifying the approach to the MV by avoiding a median sternotomy. These approaches include partial sternotomy (ministernotomy), parasternal incisions, minithoracotomy, and total endoscopic/robotic access [5-9]. The main goal is to achieve identical technical perfection with the advantages of a limited skin incision. The reported benefits include a reduced amount of blood transfusion, preserved pulmonary function, better chest stability, less postoperative pain, improved postoperative recovery, decreased hospital length of stay, and ultimately faster return to all activities of daily living [10-14]. 
In the late 1990s, we adopted a minimally invasive approach to valve surgery via partial upper sternotomy (PUS) which became a standard access in our institution for aortic, mitral, and multiple valve surgery, as well as for arch surgery over the years [15-17].

The aim of this study was to analyze the short- and long-term outcomes of isolated minimally invasive MV surgery through PUS with regard to survival, MV-related reoperation, and recurrent MV regurgitation.

\section{Materials and Methods}

\subsection{Study Population and Clinical Data}

The study was approved by the local Ethical Committee of University Hospital Frankfurt, and an informed consent was obtained from each patient.

Four-hundred-nineteen patients with the median age of 58.9 (interquartile range 18.7) years (31.7\% females), who underwent minimally invasive MV surgery via PUS at the Department of Cardiovascular Surgery, University Hospital Frankfurt from January 2004 through March 2014, were included in the study. Children and adult patients with concomitant valve, coronary, or aortic surgery were excluded from the study (Table 1).

Table 1. Preoperative characteristics.

\begin{tabular}{|c|c|c|}
\hline Variable & Median/Number/Mean & $\% / I Q R / S D$ \\
\hline Age [years] & 58.9 & 18.7 \\
\hline Female & 133 & 31.7 \\
\hline Hypertension & 326 & 53.3 \\
\hline Diabetes & 34 & 8.1 \\
\hline Peripheral vascular disease & 8 & 1.9 \\
\hline Previous stroke & 27 & 6.4 \\
\hline EuroSCORE II & 3.9 & \pm 3.6 \\
\hline Sinus rhythm & 302 & 72.1 \\
\hline Pulmonary hypertension & 147 & 35.1 \\
\hline COPD & 38 & 9.1 \\
\hline \multicolumn{3}{|l|}{ Etiology: } \\
\hline Myxomatous degenerative & 323 & 77.1 \\
\hline Posterior leaflet prolapse & 257 & 79.6 \\
\hline Bileaflet prolapse & 31 & 9.6 \\
\hline Anterior leaflet prolapse & 26 & 8.0 \\
\hline Commissural prolapse & 9 & 2.8 \\
\hline Rheumatic & 22 & 5.3 \\
\hline Infective & 32 & 7.6 \\
\hline Isolated mitral ring dilatation & 30 & 7.2 \\
\hline Other & 12 & 2.9 \\
\hline \multicolumn{3}{|l|}{ Indication: } \\
\hline Elective & 340 & 80.7 \\
\hline Urgent & 75 & 17.9 \\
\hline Emergency & 4 & 1.0 \\
\hline
\end{tabular}

Before surgery, all patients were routinely examined by transthoracic echocardiography (TTE), coronary angiography, and/or cardiac computed tomography (CT). An intraoperative transoesophageal echocardiography (TEE) was performed in all patients 
to evaluate valve function pre- and post-cardiopulmonary bypass to facilitate the surgical procedure and to assess the immediate result of the MV surgery as well as the left ventricular function during weaning from the cardio-pulmonary bypass and adequacy of de-airing of the cardiac chambers. The echocardiographic classification of residual/recurrent MV regurgitation was as follows: grade 0 -none/trace; grade 1 -mild; grade 2 -moderate; grade 3-moderately severe; and grade 4-severe.

The postoperative anticoagulation regimen included initial subcutaneous low-molecular weight heparin for the first days and in parallel oral anticoagulation with vitamin K antagonist. Oral anticoagulation was continued for 6 weeks after an uncomplicated repair and adapted to the needs of atrial fibrillation or implanted prostheses thereafter. All patients received a TTE at discharge.

All patients were followed-up prospectively and systematically by means of annually mailed questionnaires or phone interviews and/or by clinical assessment and TTE in our outpatient clinic. For patients not seen personally we retrieved the clinical assessment and echocardiography reports from the attending cardiologist.

The completeness of follow-up was calculated as the portion of the actual observed patient years divided by the maximum of observable patient years as described by Akins et al. [18]. The entry to follow-up was the date of the operation. Follow-up was calculated until: 1. knowledge of death, 2. lost to follow-up, 3. last census date (either 1 January 2015 query at local authorities or clinical follow-up within 2015), and 4. end of study on 31 December 2015. The clinical follow-up time C was $87 \%$. The median follow-up was 5.5 years (range $0-11$ ). The total follow-up was 2366 patient-years. The echocardiographic follow-up was available in $96 \%(401 / 419)$ of patients. This accounts for $47 \%$ of the study period. The median echocardiographic follow-up was 2.9 years (range 0-11).

\subsection{Surgical Technique}

The operative technique has been previously described in detail $[15,16]$. Briefly, after cross-clamping the aorta and arresting the heart using antegrade cardioplegia the MV was approached through a superior trans-septal atriotomy, in the majority of cases with extension to the left atrial roof. Several stay sutures were placed on the interatrial septum, the base of the left atrial appendage, and the mural portion of the mitral annulus to expose the MV. Exposure was further optimized after placing the annuloplasty stitches through both trigoni fibrosi. After a proper valve analysis, either an MV repair or eventually a valve replacement with mechanical or biological prosthesis was performed.

\subsection{Statistical Analysis}

Valve-related outcomes were defined according to the published guidelines [18]. Continuous and discrete variables were expressed as mean \pm SD or median and interquartile range (IQR) for data not normally distributed. Categorical and ordinal variables were expressed by number and percentage of observations. Continuous and discrete variables were compared using a two-sample t-test or Mann-Whitney test, where appropriate. The probability of freedom from event was calculated according to the Kaplan-Meier method. Survival and freedom-from-event curves were compared by log-rank test. A $p$-value $<0.05$ was considered to indicate statistical significance. A statistical analysis was performed using Stat view (Carry, NC, USA) and IBM SPSS (version 25 for MS Windows; IBM Corporation, Armonk, NY, USA).

\section{Results}

\subsection{Operative Data}

Mitral valve repair was performed in 384 patients $(91.6 \%)$ and replacement in 35 patients $(8.4 \%)$. Mainly used MV repair techniques were triangular or quadrangular resection followed by artificial chord implantation accomplished by ring annuloplasty. The majority of the patients (86\%) received an open flexible ring (Cosgrove-Edwards ring). A more detailed description of repair techniques and other perioperative characteristics are provided 
in Table 2. A second pump run to improve the repair or to replace the valve was needed in 15 patients (3.6\%). The MV was replaced in 20 cases (4.8\%) using a mechanical prosthesis and in 15 cases (3.6\%) using a biological prosthesis (Table 2).

Table 2. Operative data.

\begin{tabular}{lll}
\hline Variable & Number/Median & \%/IQR \\
\hline Mitral valve repair & 380 & 90.7 \\
\hline Triangular or quadrangular resection & 276 & 65.8 \\
\hline Artificial chord implantation & 139 & 33 \\
\hline Ring annuloplasty & 380 & 100 \\
\hline Cosgrove-Edwards ring (flexible) & 328 & 86.4 \\
\hline Carpentier-Edwards physio ring (semirigid) & 47 & 12.3 \\
\hline Profile 3D ring (rigid) & 5 & 1 \\
\hline Mitral valve replacement & 39 & 9.3 \\
\hline Mechanical prosthesis & 17 & 4.1 \\
\hline Biological prothesis & 8 & 1.9 \\
\hline Left atrial ablation & 61 & 14.5 \\
\hline Amputation or occlusion of left atrial appendage & 261 & 62.2 \\
\hline Aortic cross-clamp time [min] & 97.5 & 11.2 \\
\hline Cardio-pulmonary bypass time [min] & 144.3 & 40.0 \\
\hline IQR-interquartile range; SD—standard deviation. & &
\end{tabular}

\subsection{Early Postoperative Outcomes}

Thirty-day mortality occurred in 13 cases (3.1\%). In eight of these patients (61\%), a re-exploration due to postoperative bleeding was necessary. The cause of death was multiple organ failure in six, sepsis in three, low cardiac output syndrome in one, major stroke in one, and other causes in two patients, respectively. Other early postoperative data are shown in detail in Table 3. The TTE data at discharge are presented in Table 4.

Table 3. Early postoperative data.

\begin{tabular}{ll}
\hline Variable & Number (\%)/Median (IQR) \\
\hline Reoperation for bleeding & $31(7.3 \%)$ \\
\hline Blood loss during ICU stay [ml] & $450 / 363$ \\
\hline Myocardial infarction & $2(0.4 \%)$ \\
\hline Postoperative dialysis & $23(5.4 \%)$ \\
\hline Major neurological complications & $8(2 \%)$ \\
\hline Gastrointestinal bleeding/ischemia & $11(2.6 \%)$ \\
\hline Superficial sternal wound infection & $16(3.8 \%)$ \\
\hline Deep sternal wound infection & $4(1 \%)$ \\
\hline Postoperative pacemaker implantation & $24(5.7 \%)$ \\
\hline 30-day mortality & $13(3.1 \%)$ \\
\hline
\end{tabular}


Table 4. Echocardiographic data at discharge and follow-up.

\begin{tabular}{llll}
\hline Variable & $\begin{array}{l}\text { At Discharge } \\
\text { (Mean } \pm \text { SD) }\end{array}$ & $\begin{array}{l}\text { Last Follow-Up } \\
\text { (Mean } \pm \text { SD) }\end{array}$ & $p$-Value \\
\hline Mitral regurgitation [grade] & $0.21 \pm 0.40$ & $0.61 \pm 0.66$ & 0.01 \\
\hline LVEDD [mm] & $51.84 \pm 7.62$ & $51.78 \pm 8.79$ & 0.92 \\
\hline LVESD [mm] & $36.13 \pm 8.15$ & $35.39 \pm 9.03$ & 0.12 \\
\hline MV Pmean [mmHg] & $4.02 \pm 2.85$ & $4.17 \pm 2.89$ & 0.51 \\
\hline MVA [cm ${ }^{2}$ ] & $2.73 \pm 1.05$ & $2.44 \pm 1.13$ & 0.01 \\
\hline Left atrial diameter [mm] & $45.44 \pm 8.59$ & $45.99 \pm 8.60$ & 0.68 \\
\hline LVEF [\%] & $55.4 \pm 9.3$ & $53.7 \pm 8.8$ & 0.23 \\
\hline
\end{tabular}

LVEF—left ventricular ejection fraction; LVEDD—left ventricular end-diastolic diameter; LVESD—left ventricular end-systolic diameter; MV Pmean—mitral valve mean pressure gradient; MVA—-mitral valve orifice area; SD— standard deviation.

\subsection{Survival and Late Clinical Outcomes}

During the follow-up, $26(6.2 \%)$ patients died. The overall estimated survival at 1, 5, and 10 years was $93.1 \pm 1.3 \%, 87.1 \pm 1.9 \%$, and $81.1 \pm 3.4 \%$ (Figure 1 ). The Kaplan-Meier survival estimator for the overall cohort was $9.6 \pm 0.2$ years (CI 9.197-9.986). After dividing the overall cohort into repair versus replacement group, the survival at 5 - and 10-years was $89.3 \pm 1.8 \%$ and $82.1 \pm 4.1 \%$ vs. $53.8 \pm 12.1 \%$ and $53.8 \pm 12.1 \%(p<0.001)$, respectively.

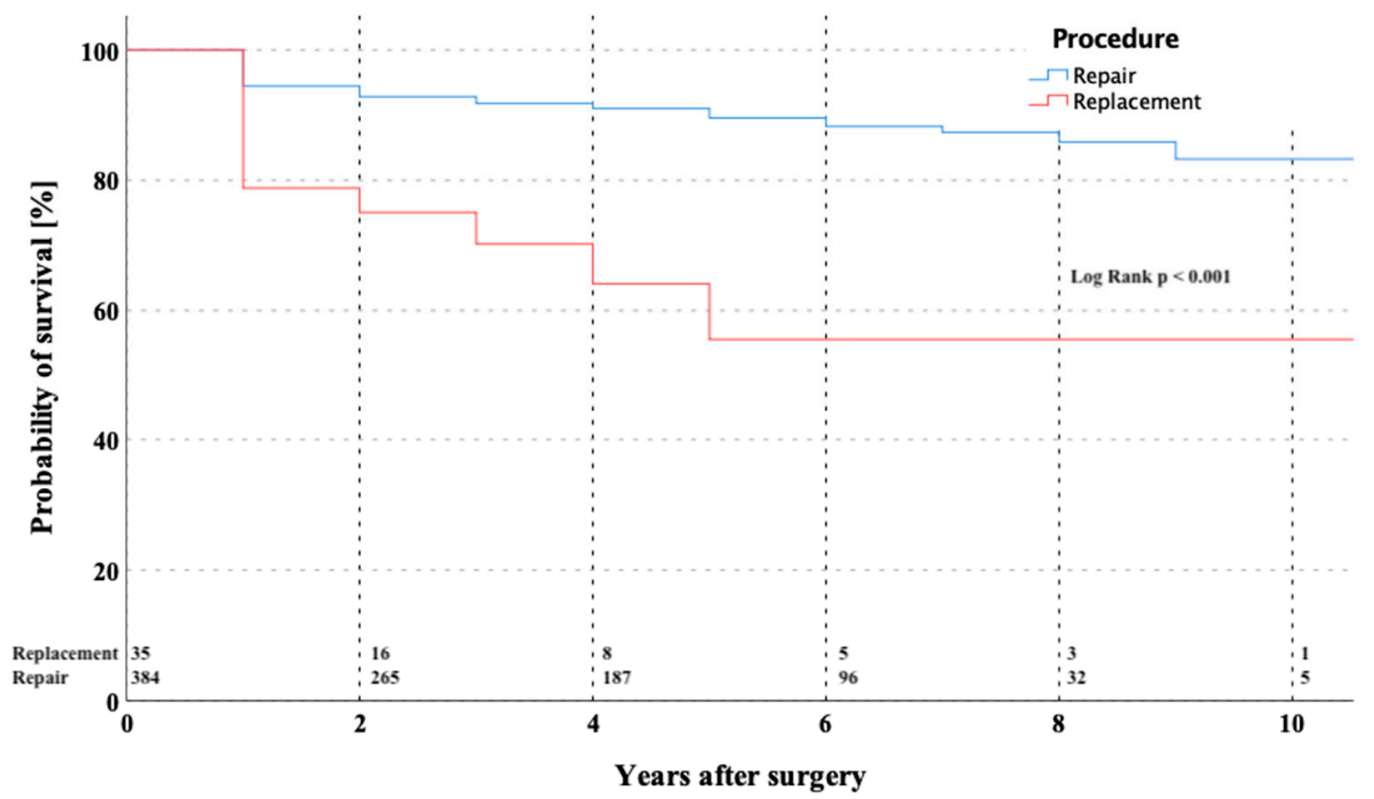

Figure 1. Kaplan-Meier curve showing survival in patients after mitral valve repair versus replacement through partial upper sternotomy.

Fourteen (3.3\%) patients required reoperation after MV repair during the followup interval due to the following reasons: annulus re-dilatation and/or recurrent leaflet prolapse in 11 and endocarditis with leaflet perforation in three patients. In four patients, re-repair of the MV was successfully performed. All reoperations were performed through the full median sternotomy. The detailed data of all reoperated patients including the exact reason of reoperation are shown in Table 5. The overall estimated freedom from MV reoperation at 1, 5, and 10 years was $98.2 \pm 0.7 \%, 96.1 \pm 1.2 \%$, and $86.7 \pm 6.7 \%$ (Figure 2). The Kaplan-Meier estimator for freedom of reoperation for the overall cohort was $10.4 \pm 2.2$ years (CI 9.940-10.823). 
The overall estimated freedom from recurrent MV regurgitation >grade 2 in repaired valves at 1, 5, and 10 years was $98.8 \pm 0.6 \%, 98.8 \pm 0.6 \%$, and $94.6 \pm 3.3 \%$ (Figure 3). The Kaplan-Meier estimator for freedom from mitral insufficiency > grade 2 was $10.8 \pm 0.15$ years (CI 10.453-11.053). No statistically significant difference was found in regard to freedom from reoperation $(p=0.95)$ or regurgitation $>2(p=0.479)$ after dividing the overall cohort into repair versus replacement groups.

The TTE data at the latest follow-up of all living and non-reoperated patients are shown in Table 4. The TTE data analysis between discharge and last follow-up was able to show a statistically significant increase in MR grade $(0.21$ to $0.61, p=0.01)$ and decrease in MV orifice area (2.73 to $2.44 \mathrm{~cm}^{2}, p=0.01$ ).

Table 5. Data of reoperated patients due to mitral valve disease.

\begin{tabular}{|c|c|c|c|c|c|c|}
\hline Patient & Age & $\begin{array}{l}\text { Incidation to } \\
\text { Operation }\end{array}$ & Operation & $\begin{array}{l}\text { Time to } \\
\text { Reoperation } \\
\text { (Years) }\end{array}$ & $\begin{array}{l}\text { Indication to } \\
\text { Reoperation }\end{array}$ & Reoperationa \\
\hline 1 & 46 & $\begin{array}{l}\text { Myxomatous } \\
\text { degenerative }\end{array}$ & MV repair & 0.01 & MV stenosis & $\begin{array}{l}\text { MV } \\
\text { replacement }\end{array}$ \\
\hline 2 & 41 & $\begin{array}{l}\text { Myxomatous } \\
\text { degenerative }\end{array}$ & MV repair & 0.03 & MV stenosis & $\begin{array}{l}\text { MV } \\
\text { replacement }\end{array}$ \\
\hline 3 & 46 & $\begin{array}{l}\text { Myxomatous } \\
\text { degenerative }\end{array}$ & $\begin{array}{l}\text { MV } \\
\text { replacement }\end{array}$ & 0.09 & $\begin{array}{l}\text { MV regurgitation due } \\
\text { to paravulvar leak }\end{array}$ & $\begin{array}{l}\text { MV } \\
\text { re-replacement }\end{array}$ \\
\hline 4 & 71 & $\begin{array}{l}\text { Myxomatous } \\
\text { degenerative }\end{array}$ & MV repair & 0.2 & $\begin{array}{l}\text { MV regurgitation due } \\
\text { to endocarditis }\end{array}$ & $\begin{array}{l}\text { MV } \\
\text { replacement }\end{array}$ \\
\hline 5 & 48 & $\begin{array}{l}\text { Myxomatous } \\
\text { degenerative }\end{array}$ & MV repair & 0.5 & $\begin{array}{l}\text { MV regurgitation due } \\
\text { to leaflet re-prolapse }\end{array}$ & MV re-repair \\
\hline 6 & 44 & Rheumatic & $\begin{array}{l}\text { MV } \\
\text { replacement }\end{array}$ & 0.6 & $\begin{array}{l}\text { MV regurgitation due } \\
\text { to paravulvar leak }\end{array}$ & $\begin{array}{l}\text { MV } \\
\text { re-replacement }\end{array}$ \\
\hline 7 & 65 & $\begin{array}{l}\text { Myxomatous } \\
\text { degenerative }\end{array}$ & MV repair & 0.8 & $\begin{array}{l}\text { MV regurgitation due } \\
\text { to leaflet re-prolapse }\end{array}$ & $\begin{array}{l}\text { MV } \\
\text { replacement }\end{array}$ \\
\hline 8 & 68 & $\begin{array}{l}\text { Myxomatous } \\
\text { degenerative }\end{array}$ & MV repair & 1.3 & MV stenosis & $\begin{array}{l}\text { MV } \\
\text { replacement }\end{array}$ \\
\hline 9 & 51 & $\begin{array}{l}\text { Myxomatous } \\
\text { degenerative }\end{array}$ & MV repair & 2 & $\begin{array}{l}\text { MV regurgitation due } \\
\text { to annulus re-dilatation }\end{array}$ & MV re-repair \\
\hline 10 & 44 & $\begin{array}{l}\text { Acute } \\
\text { endocarditis }\end{array}$ & MV repair & 2.2 & $\begin{array}{l}\text { MV regurgitation due } \\
\text { to re-ndocarditis }\end{array}$ & $\begin{array}{l}\text { MV } \\
\text { replacement }\end{array}$ \\
\hline 11 & 56 & $\begin{array}{l}\text { Degenerative/ } \\
\text { calcification }\end{array}$ & MV repair & 3 & $\begin{array}{l}\text { MV regurgitation due } \\
\text { to annulus re-dilatation }\end{array}$ & MV re-repair \\
\hline 12 & 49 & $\begin{array}{l}\text { Myxomatous } \\
\text { degenerative }\end{array}$ & MV repair & 6 & MV stenosis & $\begin{array}{l}\text { MV } \\
\text { replacement }\end{array}$ \\
\hline 13 & 46 & $\begin{array}{l}\text { Myxomatous } \\
\text { degenerative }\end{array}$ & MV repair & 6 & $\begin{array}{l}\text { MV regurgitation due } \\
\text { to leaflet re-prolapse }\end{array}$ & MV re-repair \\
\hline 14 & 51 & $\begin{array}{l}\text { Degenerative/ } \\
\text { calcification }\end{array}$ & MV repair & 8 & $\begin{array}{l}\text { MV regurgitation due } \\
\text { to endocarditis }\end{array}$ & $\begin{array}{l}\text { MV } \\
\text { replacement }\end{array}$ \\
\hline
\end{tabular}




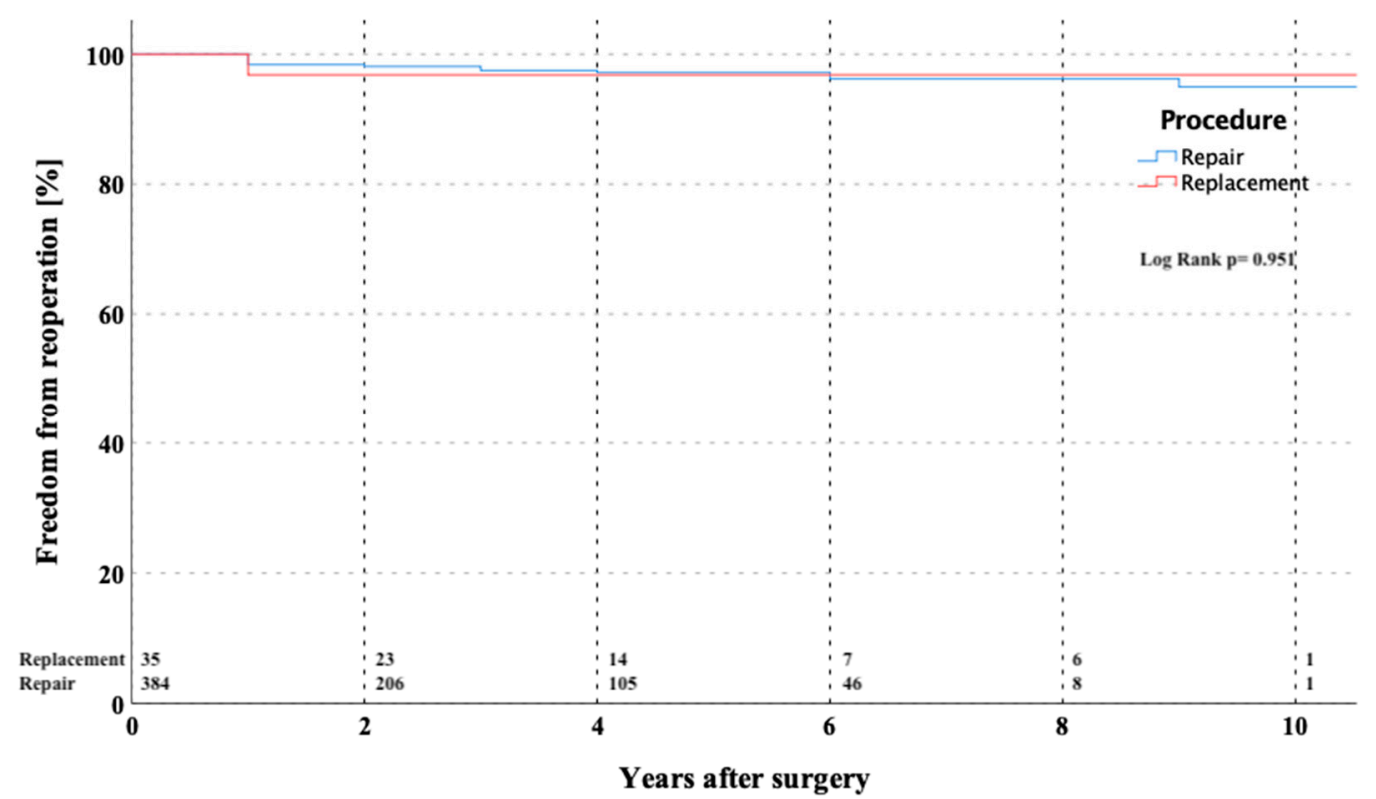

Figure 2. Kaplan-Meier curve showing freedom from MV-related reoperation in patients after MV repair versus replacement through partial upper sternotomy. MV—mitral valve.

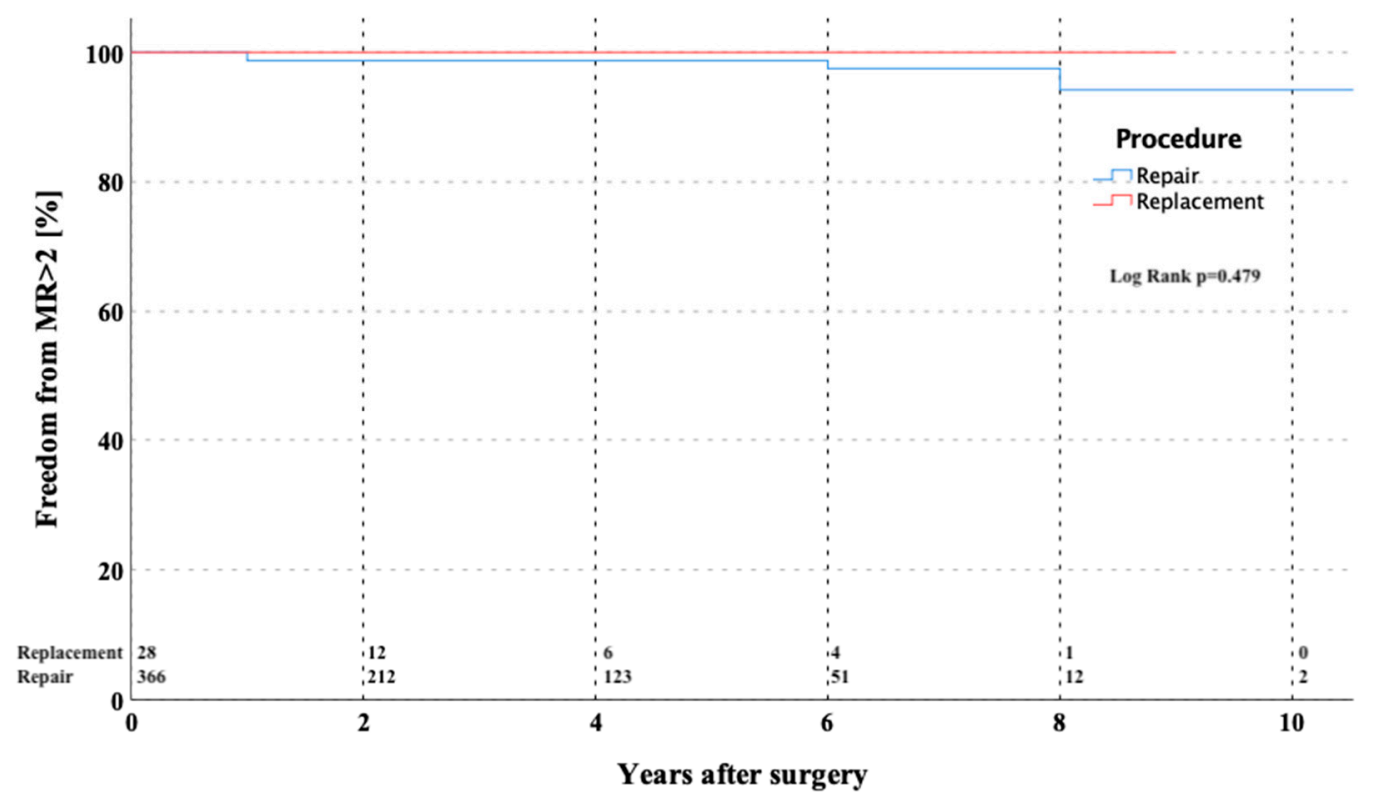

Figure 3. Kaplan-Meier curve showing freedom from MR > grade 2 in patients after MV repair versus replacement through partial upper sternotomy. MR—-mitral valve regurgitation; MV—mitral valve.

\section{Discussion}

Mitral valve surgery including repair or replacement, especially in complex pathologies, can be a challenging cardio-surgical procedure. Despite this fact, many surgeons worldwide perform MV surgery using a minimally invasive approach. This trend is supported by currently available evidence. Cheng and colleagues suggested minimally invasive MV surgery to be associated with decreased bleeding, blood transfusion, atrial fibrillation, sternal wound infections, ventilation time, intensive care unit stay, and length of hospital stay, and more expeditious return to the normal physical activity, whereas no differences in survival and valve re-intervention in the long-term were found [19]. 
As a surgical technique, two different minimally invasive access modalities to the MV are currently available, accepted, and under widespread clinical use: 1. right lateral minithoracotomy (direct-vision, video-assisted, total endoscopic, and robotic) with usually peripheral cannulation; and 2. PUS with central cannulation and a trans-septal approach to the MV. For the surgeon who decides to use a minimally invasive approach for MV operation a decision has to be made mainly based on the type of incision and the way of cannulation. Whereas right lateral minithoracotomy MV surgery usually is performed together with retrograde femoral perfusion, the PUS technique can be applied together with standard antegrade aortic perfusion. Thus, it is a potentially valid therapeutic approach whenever retrograde femoral perfusion should be avoided (e.g., in severe peripheral arterial occlusive disease, severe plaques in the aorta, etc.), and is quite similar for patients where right lateral minithoracotomy should be avoided (e.g., previous surgery in this field leading to adhesions, severe lung disease, etc.).

In the past years, PUS has become an attractive and frequently used approach for minimally invasive aortic valve replacement [20]. Moreover, the indications for this minimally invasive approach were extended to even more complex operations, which can be safely performed via PUS $[16,17,21-23]$. In our department, we expanded the indication for this minimally invasive access and have been using it as a standard surgical approach to the MV even with concomitant tricuspid and/or aortic valve surgery starting in 1998 . The PUS access may be performed to the left or right fourth intercostal spaces. In our practice, we performed it in the left fourth intercostal space. The advantages of extending the PUS to the left fourth intercostal space are as follows: 1 . the heart lies in the thorax more to the left than to the right of the midline, 2. the MV is more easily accessible using the left instead of the right extension of the PUS, and 3. the surgeon does not have to work under the sternum, as is necessary when the PUS ends up in the right intercostal space.

The current study shows very good results of 419 minimally invasive MV procedures via PUS in an all-comers cohort with a 30-day mortality of 3.1\%. Seeburger and colleagues reported outcomes in a series of 1.536 consecutive patients who underwent minimally invasive MV surgery for regurgitation through a right lateral minithoracotomy with a 30 -day mortality of $2.4 \%$ [24]. Due to an all-comers population in our study, the 30-day mortality of $3.1 \%$ seems elevated, but with a mean EuroSCORE II of $3.9 \pm 3.6 \%$ expected, the observed mortality seems to be favorable. The overall survival at 5 and 10 years was $87.1 \pm 1.9 \%$ and $81.1 \pm 3.4 \%$, respectively. Patients undergoing MV replacement had a higher risk of mortality in the follow-up $(p<0.001)$, which is probably due to the fact that these patients had a higher risk profile, rather than to the procedure itself. The 5-year survival of our patients receiving repair only of $89.3 \pm 1.8 \%$ was even better compared to Seeburger's series of $82.6 \%$ [24].

The freedom from MV-related reoperation and freedom from recurrent MV mitral insufficiency > grade 2 at 5 years: $96.1 \pm 1.6 \%$ and $98.8 \pm 0.6 \%$ and at 10 years: $86.7 \pm 6.7 \%$ and $94.6 \pm 3.3 \%$ respectively, were encouraging. The freedom from reoperation in Seeburger's series was quite similar with 96.3\% [24]. In a meta-analysis performed by Sündermann and colleagues published in 2014 including more than 20,000 patients from 45 studies, a perioperative morbidity following MV surgery has been reported [25]. The incidence of major neurological events following MV surgery via right antero-lateral minithoracotomy was $1.7 \%$, which is comparable to our results with an incidence of major neurological events of $2 \%$. The median of chest tube drainage during ICU stay in our cohort was $450 \mathrm{~mL}$, which is also in line with this study.

The analysis comparing TTE data at discharge and at last follow-up (Table 4) revealed a solid performance of MV surgery via PUS approach; however, a slightly increasing MR grade $(0.21$ to $0.61, p=0.01)$ over the follow-up period was observed. One of the reasons for the increase could be that the majority of the patients received an open flexible ring (Cosgrove-Edwards ring). Annular re-dilatation with this ring has been described and is possible, thus it could lead to recurrence of the MR. Additionally, in two of the reoperated patients an annular re-dilatation was observed and both patients were initially implanted 
with a Cosgrove-Edwards ring. Another finding was a slightly decreasing MV orifice area ( 2.73 to $2.44 \mathrm{~cm}^{2}, p=0.01$ ). Due to this fact, one can postulate that this is not the acute effect of annuloplasty with strong ring downsizing, but rather the effect of MV disease evolution and progression after MV repair with leaflet repair and annuloplasty sutures.

Despite the stimulating results and some potential benefits of the PUS approach using transseptal access to the MV, there is definitely at least one major drawback. The increased rate of postoperative pacemaker implantation in nearly $5 \%$ of patients was slightly higher than in the literature of the minithoracotomy approach. However, it is comparable to other studies using the PUS access, as Oezpeker and colleagues reported a postoperative permanent pacemaker implantation rate of $4 \%$ in 103 patients [26]. The reported incidence of postoperative AV-block and subsequent pacemaker implantation can probably be explained by the possible injury of the conduction system through the transseptal access to the MV. Due to this drawback and because of the technically very demanding access to the MV via the interatrial groove in the PUS approach, some other groups considered different access to the MV. Little and colleagues proposed the left atrial dome incision as an optional access to the MV in the PUS approach [27]. They described their initial experience with this technique and concluded that adequate visualization of the MV for standard repair or replacement can be achieved. Additionally, this approach rarely divides the sinus node artery and therefore the rate of postoperative AV-block remains significantly lower than in the transseptal access. There are several limitations of this study. This was a retrospective, single-centre, non-randomized, observational study, and all inherent disadvantages apply. Additionally, the inability to determine the late causes of death and a lack of complete follow-up could be limiting.

\section{Conclusions}

This study provides short- and long-term results of minimally invasive MV surgery via PUS in a large all-comers cohort of patients. The results indicate that it can be performed safely with very good early and late results in both MV repair and replacement. In fact, the minimally invasive MV surgery via right antero-lateral minithoracotomy and peripheral cannulation is currently becoming more popular and has been adopted in the majority of centers, including our department. However, this approach demands a completely different setting, equipment, instruments, and especially thinking of the operating team. We therefore believe that the PUS approach with the use of standard surgical instruments and cannulation techniques can be a valuable alternative option for the MV surgery either in patients contraindicated or not suitable for minithoracotomy or in centers not willing or not able to establish the latter. In addition, the PUS access can even be easily extended to be used in patients requiring multiple valve surgery.

Author Contributions: Conceptualization, M.R., P.R., A.M. (Anton Moritz), and T.H.; methodology, M.R., A.M. (Aleksandra Miskovic), and A.M. (Anton Moritz); data curation, M.R. and C.S.; statistical analysis, C.S. and T.H.; writing- original draft preparation, M.R. and F.H.; writing-review and editing, F.H., J.H., A.M. (Anton Moritz), T.W., and T.H.; supervision, A.M. (Anton Moritz), T.W., and T.H. All authors have read and agreed to the published version of the manuscript.

Funding: There was no funding for this study.

Institutional Review Board Statement: The study was approved by the local Ethical Committee of University Hospital Frankfurt (approval code 79/13 on 4 April 2013).

Informed Consent Statement: Patient consent was waived due to the retrospective analysis of clinical data.

Data Availability Statement: No additional data included.

Conflicts of Interest: All authors declare they have no disclosure in relation to this study. 


\section{References}

1. Iribarne, A.; Karpenko, A.; Russo, M.J.; Cheema, F.; Umann, T.; Oz, M.C.; Smith, C.R.; Argenziano, M. Eight-year experience with minimally invasive cardiothoracic surgery. World J. Surg. 2010, 34, 611-615. [CrossRef]

2. Totaro, P.; Carlini, S.; Pozzi, M.; Pagani, F.; Zattera, G.; D'Armini, A.M.; Vigano, M. Minimally invasive approach for complex cardiac surgery procedures. Ann. Thorac. Surg. 2009, 88, 462-466, discussion 7. [CrossRef] [PubMed]

3. Kypson, A.P. Recent trends in minimally invasive cardiac surgery. Cardiology 2007, 107, 147-158. [CrossRef] [PubMed]

4. Mack, M.J. Minimally invasive cardiac surgery. Surg. Endosc. 2006, 20 (Suppl. S2), S488-S492. [CrossRef]

5. Vanermen, H.; Farhat, F.; Wellens, F.; Geest, R.; Degrieck, I.; Praet, F.; Vermeulon, Y. Minimally invasive video-assisted mitral valve surgery: From port-access towards a totally endoscopic procedure. J. Card. Surg. 2000, 15, 51-60. [CrossRef] [PubMed]

6. Tatooles, A.J.; Pappas, P.S.; Gordon, P.J.; Slaughter, M.S. Minimally invasive mitral valve repair using the da vinci robotic system. Ann. Thorac. Surg. 2004, 77, 1978-1982, discussion 82-84. [CrossRef]

7. Mishra, Y.K.; Malhotra, R.; Mehta, Y.; Sharma, K.K.; Kasliwal, R.R.; Trehan, N. Minimally invasive mitral valve surgery through right anterolateral minithoracotomy. Ann. Thorac. Surg. 1999, 68, 1520-1524. [CrossRef]

8. Karagoz, H.Y.; Bayazit, K.; Battaloglu, B.; Kurtoglu, M.; Özerdem, G.; Bakkaloglu, B.; Sönmez, B. Minimally invasive mitral valve surgery: The subxiphoid approach. Ann. Thorac. Surg. 1999, 67, 1328-1332, discussion 33. [CrossRef]

9. Grossi, E.A.; Galloway, A.C.; LaPietra, A.; Ribakove, G.H.; Ursomanno, P.; Delianides, J.; Culliford, A.T.; Bizekis, C.; Esposito, R.A.; Baumann, F.; et al. Minimally invasive mitral valve surgery: A 6-year experience with 714 patients. Ann. Thorac. Surg. 2002, 74, 660-663, discussion 3-4. [CrossRef]

10. Modi, P.; Hassan, A.; Chitwood, W.R.J. Minimally invasive mitral valve surgery: A systematic review and meta-analysis. Eur. J. Cardiothorac. Surg. 2008, 34, 943-952. [CrossRef]

11. Cohn, L.H.; Adams, D.H.; Couper, G.S.; Bichell, D.; Rosborough, D.M.; Sears, S.P.; Aranki, S.F. Minimally invasive cardiac valve surgery improves patient satisfaction while reducing costs of cardiac valve replacement and repair. Ann. Surg. 1997, 226, 421-426, discussion 7-8. [CrossRef] [PubMed]

12. Yamada, T.; Ochiai, R.; Takeda, J.; Shin, H.; Yozu, R. Comparison of early postoperative quality of life in minimally invasive versus conventional valve surgery. J. Anesth. 2003, 17, 171-176. [CrossRef] [PubMed]

13. Grossi, E.A.; Galoway, A.; Ribakove, G.H.; Zakow, P.K.; Derivaux, C.C.; Baumann, F.; Schwesinger, D.; Colvin, S.B. Impact of minimally invasive valvular heart surgery: A case-control study. Ann. Thorac. Surg. 2001, 71, 807-810. [CrossRef]

14. de Vaumas, C.; Philip, I.; Daccache, G.; Depoix, J.-P.; Lecharny, J.-B.; Enguerand, D.; Desmonts, J.-M. Comparison of minithoracotomy and conventional sternotomy approaches for valve surgery. J. Cardiothorac. Vasc. Anesth. 2003, 17, 325-328. [CrossRef]

15. Radwan, M.; Bon, D.; Dressen, L.; Walther, T.; Miscovic, A.; Moritz, A.; Papadopoulos, N. Propensity-matched comparison of two different access modes for minimally invasive mitral valve surgery. Semin. Thorac. Cardiovasc. Surg. 2020, 32, 36-44. [CrossRef] [PubMed]

16. Risteski, P.; Monsefi, N.; Miskovic, A.; Josic, T.; Bala, S.; Salem, R.; Zierer, A.; Moritz, A. Triple valve surgery through a less invasive approach: Early and mid-term results. Interact. Cardiovasc. Thorac. Surg. 2017, 24, 677-682. [CrossRef] [PubMed]

17. Risteski, P.; Ahmad, A.E.-S.; Monsefi, N.; Papadopoulos, N.; Radacki, I.; Herrmann, E.; Moritz, A.; Zierer, A. Minimally invasive aortic arch surgery: Early and late outcomes. Int. J. Surg. 2017, 45, 113-117. [CrossRef] [PubMed]

18. Akins, C.W.; Miller, D.C.; Turina, M.I.; Kouchoukos, N.T.; Blackstone, E.H.; Grunkemeier, G.L.; Takkenberg, J.; David, T.E.; Butchart, E.G.; Adams, D.H.; et al. Guidelines for reporting mortality and morbidity after cardiac valve interventions. J. Thorac. Cardiovasc. Surg. 2008, 135, 732-738. [CrossRef]

19. Cheng, D.C.H.; Martin, J.; Lal, A.; Diegeler, A.; Folliguet, T.A.; Nifong, L.W.; Perier, P.; Raanani, E.; Smith, J.M.; Seeburger, J.; et al. Minimally invasive versus conventional open mitral valve surgery: A meta-analysis and systematic review. Innovations 2011, 6, 84-103. [CrossRef]

20. Malaisrie, S.C.; Barnhart, G.R.; Farivar, R.S.; Mehall, J.; Hummel, B.; Rodriguez, E.; Anderson, M.; Lewis, C.; Hargrove, C.; Ailawadi, G.; et al. Current era minimally invasive aortic valve replacement: Techniques and practice. J. Thorac. Cardiovasc. Surg. 2014, 147, 6-14. [CrossRef]

21. Kaneko, T.; Couper, G.S.; Borstlap, W.A.; Nauta, F.J.; Wollersheim, L.; McGurk, S.; Cohn, L.H. Minimal-access aortic valve replacement with concomitant aortic procedure: A 9-year experience. Innovations 2012, 7, 368-371. [CrossRef]

22. Shrestha, M.; Krueger, H.; Umminger, J.; Koigeldiyev, N.; Beckmann, E.; Haverich, A.; Martens, A. Minimally invasive valve sparing aortic root replacement (david procedure) is safe. Ann. Cardiothorac. Surg. 2015, 4, 148-153. [PubMed]

23. Franke, U.F.W.; Ursulescu, A.; Göbel, N.; Nagib, R.; Hansen, M.; Yadav, R.; Baumbach, H.; Albert, M. Results and quality of life after minimally invasive ross procedure. J. Heart Valve Dis. 2015, 24, 295-301. [PubMed]

24. Seeburger, J.; Borger, M.; Falk, V.; Kuntze, T.; Czesla, M.; Walther, T.; Doll, N.; Mohr, F.W. Minimal invasive mitral valve repair for mitral regurgitation: Results of 1339 consecutive patients. Eur. J. Cardiothorac. Surg. 2008, 34, 760-765. [CrossRef] [PubMed]

25. Sündermann, S.H.; Sromicki, J.; Biefer, H.R.C.; Seifert, B.; Holubec, T.; Falk, V.; Jacobs, S. Mitral valve surgery: Right lateral minithoracotomy or sternotomy? A systematic review and meta-analysis. J. Thorac. Cardiovasc. Surg. 2014, 148, 1989-1995.e4. [CrossRef] 
26. Oezpeker, C.; Barbieri, F.; Hoefer, D.; Schneider, B.; Bonaros, N.; Grimm, M.; Mueller, L. Mitral valve surgery via partial upper sternotomy: Closing the gap between conventional sternotomy and right lateral minithoracotomy. Thorac. Cardiovasc. Surg. 2019, 67, 524-530. [CrossRef] [PubMed]

27. Little, S.; Flynn, M.; Pettersson, G.B.; Gillinov, A.M.; Blackstone, E.H. Revisiting the dome approach for partial sternotomy/minimally invasive mitral valve surgery. Ann. Thorac. Surg. 2009, 87, 694-697. [CrossRef] 